\title{
Desempenho operacional do conjunto trator-recolhedora de feijão
}

\author{
Operational performance of a pull-type bean combine
}

\author{
Rouverson Pereira da Silva ${ }^{I^{*}}$ Leandro Daniel Reis ${ }^{\text {II }}$ Gustavo Naves dos Reis ${ }^{\text {II }}$ \\ Carlos Eduardo Angeli Furlani' ${ }^{I}$ Afonso Lopes ${ }^{I}$ Jorge Wilson Cortez $^{\text {II }}$
}

\section{RESUMO}

A colheita mecanizada do feijão apresenta altos custos. Além disso, as características botânicas e a alta tendência ao acamamento do feijoeiro dificultam o uso de colhedoras combinadas. $O$ presente trabalho teve como objetivo avaliar o desempenho operacional do conjunto trator-recolhedoratrilhadora de feijão e quantificar as perdas ocasionadas durante a colheita, em Jaboticabal, SP. Foi utilizado delineamento inteiramente casualizado, com fatorial $2 \times 3$, combinando-se dois sistemas de preparo de solo (convencional e plantio direto) $e$ três velocidades teóricas de trabalho (V1, V2 e V3, correspondendo a 4,0;4,9 e 5,8km $h^{-1}$, respectivamente), com quatro repetições, totalizando 24 observações. O nível de ruído, os consumos volumétrico e ponderal, a taxa de alimentação da máquina, a matéria seca e a densidade da palhada, as perdas na plataforma da recolhedora e totais não são influenciadas pelos sistemas de preparo do solo (preparo convencional e plantio direto) e pelas velocidades de trabalho. As perdas ocorridas no sistema de trilha, separação e limpeza são menores na velocidade de $4,9 \mathrm{~km} \mathrm{~h}^{-1}$.

Palavras-chave: colheita mecanizada, consumo de combustível, perdas na colheita.

\section{ABSTRACT}

Mechanized harvesting of beans has a high cost. On the other hand, the botanical characteristics and the high tendency for lodging of bean planting make the combined use of harvesters difficult. This paper aimed to evaluate the operational performance of the pull-type bean combine and to quantify losses in bean harvest. The experiment was carried out in the experimental field of the São Paulo State University in the city of Jaboticabal, SP, Brazil. The field trial was in randomized blocks, in a $2 \times 3$ factorial scheme, combining two soil tillage systems (conventional and no-tillage) and three theoretical working speeds (V1,V2 and V3, respectively 4.0, 4.9 and $\left.5.8 \mathrm{~km} \mathrm{~h}^{-1}\right)$. Four repetitions of the scheme totaled up
24 observations. The analyzed factors (tillage systems and working speeds) did not affect noise level, volume and weight of fuel consumption, machine feeding flow, dry matter and straw density, losses at the harvester platform and total losses. The losses with threshing, separation and cleaning were lesser in the $4.9 \mathrm{~km} \mathrm{~h}^{-1}$ speed.

Key words: mechanical harvesting, fuel consumption, harvesting losses.

\section{INTRODUÇÃO}

O Brasil é um grande produtor de feijão, com previsão de atingir, na safra 2006/2007 (CONAB,(2007), a produção de 3,3 milhões de toneladas, com produtividade média de $817 \mathrm{~kg} \mathrm{ha}^{-1}$. De acordo com SANTOS \& BRAGA (1998), desde a década de 80 o feijoeiro passou também a ser cultivado por médios e grandes produtores, tornando-se uma cultura tecnificada, com maior produtividade e produto final de melhor qualidade, devido principalmente ao aumento das áreas irrigadas nas regiões Centro-Oeste e Sudeste.

Entre as etapas do ciclo operacional de uma cultura, a colheita se destaca em razão das dificuldades apresentadas e do alto custo agregado, seja ela realizada mecânica ou manualmente (MORAES et al., 1996). Na cultura do feijoeiro, as dificuldades são ainda maiores, pois, devido às suas características botânicas, há maior facilidade de deiscência das vagens ocasionada pelo estádio de desenvolvimento e por condições da cultura, tais como pragas, doenças e plantas daninhas. Por se tratar de planta com hábito

IDepartamento de Engenharia Rural, Universidade Estadual Paulista (UNESP), 14884-900, Campus de Jaboticabal, Jaboticabal, SP, Brasil. E-mail: rouverson@fcav.unesp.br. *Autor para correspondência.

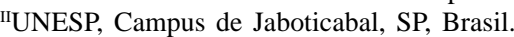


prostrado, a utilização de colhedoras combinadas pode resultar em elevadas perdas com operação de colheita (ALCÂNTARA et al., 1991). De acordo com SILVA \& FONSECA(1996) e SILVA \& SILVEIRA(2004), em geral, o feijoeiro possui muitas vagens próximas do solo, fora do alcance das lâminas de corte das colhedoras, o que dificulta sobremaneira o uso de colhedoras combinadas.

De modo geral, são três os sistemas empregados na colheita do feijoeiro: o manual, o semimecanizado e o mecanizado (SILVA, 2004). No primeiro sistema, o arranquio, o recolhimento e a trilha são realizados manualmente, arrancando-se as plantas inteiras, a partir da maturação fisiológica das sementes. As plantas arrancadas permanecem na lavoura, em molhos com as raízes para cima, para completar o processo de secamento até os grãos atingirem cerca de 16 a 18\% de umidade (ELIAS et al., 1999). Em seguida, são postas em terreiros onde se processa a batedura com varas flexíveis. No sistema semimecanizado, o arranquio e o enleiramento das plantas são, normalmente, manuais, e a trilha é realizada com auxílio de trilhadoras estacionárias ou recolhedorastrilhadoras. No sistema mecanizado, todas as operações da colheita são feitas com máquinas, de forma direta ou indireta. Na colheita mecanizada direta, são empregadas colhedoras combinadas, que realizam simultaneamente todas as operações, enquanto que na colheita indireta se utilizam equipamentos como o ceifador enleirador e a recolhedora-trilhadora em operações distintas (SILVA, 2004). No sistema mecanizado direto, partes das plantas que ainda se encontram verdes liberam umidade que, juntamente com a terra, acabam por sujar o feijão.

Procurando estudar as características da colheita direta de feijão, SILVA et al. (1999) avaliaram o efeito de três velocidades de operação de uma colhedora automotriz sobre a altura de corte e a perda de sementes na colheita de três cultivares e uma linhagem de feijão em sistema de plantio direto irrigado. Os autores concluíram que, em solo com superfície plana, desprovida de curvas de nível e de sulcos, a altura média de corte do feijoeiro com colhedora combinada foi de 113mm. Eles observaram também que, nestas condições, a perda de sementes na colheita direta do feijoeiro variou de 6,2\% na cultivar "Pérola" a 15,0\% na cultivar "Carioca". O comportamento de três métodos de colheita do feijoeiro em função de diversos manejos, com o emprego de diferentes velocidades de semeadura, foi avaliado por SILVA et al. (2005). De acordo com os resultados obtidos, os autores concluíram que a colheita mecanizada indireta proporcionou perda de grãos menor ou igual ao método direto. Além disso, a perda de ambos métodos foram superiores à perda do método semimecanizado, com arranquio manual e recolhimento e trilha mecanizados.

Os principais parâmetros que afetam o consumo de energia durante o processo de colheita mecânica são a velocidade periférica, o diâmetro e o momento de inércia do cilindro trilhador, a abertura entre cilindro e côncavo, o tipo e as dimensões do côncavo, além das características físico-mecânicas da cultura e da taxa de alimentação (MANTILLA \& RAMOS, 1998). Ao verificar o desempenho das máquinas destinadas à colheita do feijão para permitir a seleção do trator adequado para sua operação, SOUZA (2001) observou que a potência exigida para tracionar a colhedora, com carregamento máximo do tanque graneleiro, foi equivalente a 7,90kW e que o acionamento dos órgãos internos demandou 45,28kW.

Pressupondo-se que os sistemas de preparo do solo, aliados a diferentes velocidades de deslocamento, podem afetar o desempenho do conjunto trator recolhedora e as perdas na colheita, este trabalho teve como objetivo avaliar um conjunto trator-recolhedora de feijão, em dois sistemas de preparo de solo e três velocidades de deslocamento, determinando o desempenho operacional e as perdas durante a colheita.

\section{MATERIAL E MÉTODOS}

O experimento foi conduzido em área Demonstrativa e Experimental de Irrigação do Departamento de Engenharia Rural da UNESP/ Jaboticabal, SP, sob sistema de irrigação por tipo pivô central, em área de 4,3ha, localizada nas coordenadas geodésicas $21^{\circ} 14^{\prime}$ Latitude S e $48^{\circ} 17^{\prime}$ Longitude W, com altitude média de $614 \mathrm{~m}$, declividade média de $8 \%$ e clima Cwa (subtropical), de acordo com a classificação de Köeppen. O solo da área experimental foi classificado como LATOSSOLO VERMELHO Eutroférrico (EMBRAPA, 1999).

A área sob pivô central foi manejada com sucessão das culturas do feijoeiro, na época mais seca do ano, e do milho, na época mais úmida, sob sistema convencional (SC) e sistema plantio direto (SPD). Antes da instalação da cultura do feijoeiro, aplicou-se herbicida glifosato na dose de $4 \mathrm{~L} \mathrm{ha}{ }^{-1} \mathrm{em}$ toda a área, sendo utilizada a cultivar "IAC-Carioca” precoce. A cultura foi implantada no espaçamento entre linhas de $0,45 \mathrm{~m}$ e 14 sementes $\mathrm{m}^{-1}$. A adubação de semeadura utilizada foi $50 \mathrm{~kg} \mathrm{ha}^{-1}$ de uréia, $400 \mathrm{~kg} \mathrm{ha}^{-1}$ de superfosfato simples, e $75 \mathrm{~kg} \mathrm{ha}^{-1}$ de cloreto de potássio, de acordo com análise química do solo. A adubação de cobertura foi feita aplicando-se aproximadamente $150 \mathrm{~kg}$ ha ${ }^{-1}$ de uréia, aos 27 dias após a emergência, com 
adubadora pendular Vicon e, em seguida, irrigou-se com lâmina de $5 \mathrm{~mm}$ para a incorporação do adubo ao solo.

O delineamento experimental foi inteiramente casualizado, com fatorial $2 \times 3$, combinando-se dois sistemas de preparo do solo (SC e SPD) e três velocidades de trabalho, definidas por meio da seleção de três marchas indicadas pelo fabricante da recolhedora (V1, V2 e V3, correspondendo às velocidades teóricas de 4,0; 4,9 e 5,8 $\mathrm{km} \mathrm{h}^{-1}$, respectivamente), com quatro repetições, totalizando 24 parcelas demarcadas com $30 \mathrm{~m}$ de comprimento e intervalos de $15 \mathrm{~m}$ entre si, espaços estes destinados às manobras. Os dados foram submetidos à análise de variância e ao teste de médias de Tukey a 5\% de probabilidade. Para avaliação do desempenho do conjunto trator-recolhedora, foram avaliados os seguintes parâmetros: nível de ruído na cabine do operador, capacidade de campo operacional e consumo horário de combustível (volumétrico e ponderal). Estes parâmetros representam uma medida do comportamento da máquina sob condições reais de operação, nas mãos do usuário, refletindo uma interação entre as constantes construtivas, as variáveis operacionais e as condições de manejo do conjunto mecanizado (MIALHE, 1996).

Para a medição do nível de ruído na cabine do operador, utilizou-se um medidor de nível de pressão sonora da marca Extech Instruments ${ }^{\circledR}$, modelo 407706, com escalas de baixa e alta intensidade de 40 a 80 e 80 a $120 \mathrm{~dB}$, respectivamente, calibrado com áudio calibrador, marca Extech Instruments ${ }^{\circledR}$, modelo 407744. Nas medições de ruído, utilizou-se circuito de compensação "A" do medidor de pressão sonora. Portanto os valores medidos em $\mathrm{dB}(\mathrm{A})$ representam o número de pressão sonora equalizado de acordo com a curva "A" do aparelho, padronizada internacionalmente - Normas IEC 651 e EB 386, citadas pela NBR-9999 (ASSOCIAÇÃO..., 1987). Os resultados encontrados foram comparados com os limites de tolerância estabelecidos pela NR-15 (MINISTÉRIO DO TRABALHO ..., 2003).

A capacidade de campo operacional (equação 1) foi determinada com base na largura da plataforma de recolhimento $(1,62 \mathrm{~m})$, na velocidade real de deslocamento do conjunto em cada parcela e na eficiência de trabalho da operação de recolhimento, que foi de $75 \%$. Para determinar a velocidade real de deslocamento, utilizou-se uma unidade móvel de radar do tipo RVS II, colocada na lateral direita da parte inferior do trator, formando um ângulo de $45^{\circ}$ com o solo.

$$
\text { CCO }=\frac{L . V . E f}{10}
$$

em que, Cco: Capacidade de campo operacional (ha $\left.\mathrm{h}^{-1}\right)$; L: Largura da plataforma de recolhimento (m); V: Velocidade real de deslocamento $\left(\mathrm{km} \mathrm{h}^{-1}\right)$; Ef: Eficiência de campo da recolhedora-trilhadora $(0,75)$; 10 : fator de adequação das unidades.

O consumo de combustível foi medido com a utilização de um protótipo desenvolvido por LOPES et al. (2003), que consiste em dois medidores de fluxo instalados em série e dois medidores de temperatura para quantificar o débito de combustível e a temperatura do mesmo, no momento do experimento. Os consumos horário volumétrico e ponderal foram calculados por meio das equações (2) e (3), respectivamente.

$$
\begin{aligned}
& C h v=\frac{(F e-F r) \cdot 3,6}{T} \\
& C h p=C h v \cdot d
\end{aligned}
$$

em que, Chv: consumo volumétrico $\left(\mathrm{L} \mathrm{h}^{-1}\right)$; Fe: fluxo de entrada na bomba injetora registrado pelo micrologger (mL); Fr: fluxo de retorno registrado medido pelo micrologger $(\mathrm{mL})$; T: tempo para percorrer a parcela (s); Chp: Consumo ponderal $\left(\mathrm{kg} \mathrm{h}^{-1}\right)$; d: densidade do combustível $\left(\mathrm{kg} \mathrm{L}^{-1}\right)$, obtida por meio de regressão linear.

Para a aquisição e o armazenamento dos dados relativos ao desempenho do conjunto, utilizouse sistema de aquisição de dados do tipo Micrologger, da marca Campbell Scientific Inc. ${ }^{\circledR}$, modelo CR23X, posicionado na cabine do trator.

$\mathrm{O}$ arranquio e o enleiramento das plantas foram realizados de forma manual, formando-se leiras de quatro linhas, que foram posteriormente recolhidas por uma recolhedora-trilhadora DOUBLE MASTER III, com sistema de fluxo axial, tracionada por trator e acionada pela TDP, com largura de trabalho de 1,62m e rotação do cilindro trilhador de 540rpm, tracionada pelo trator Valtra, modelo BM 100, 4x2 TDA, com potência de $73,6 \mathrm{~kW}(100 \mathrm{cv})$ no motor a 2350rpm. Para determinação da umidade dos grãos, foram retiradas amostras na caçamba graneleira da máquina durante o processo de recolhimento das plantas de feijão, que posteriormente foram levadas ao laboratório para pesagem. Em seguida, as amostras foram colocadas em recipiente próprio e levadas à estufa com temperatura de $105^{\circ} \mathrm{C}$ e, após 48 horas, foram determinadas novamente as massas, obtendo-se assim o teor médio de água dos grãos no momento da colheita, que foi de $10 \%$.

A avaliação das perdas de grãos foi realizada por meio de determinações no campo utilizando-se armação de madeira com área de $2 \mathrm{~m}^{2}$ (1,62 x 1,24m), 
colocada no sentido transversal ao plantio das linhas, conforme metodologia da Embrapa (MESQUITA \& GAUDÊNCIO, 1982). Foram determinadas as perdas na pré-colheita com amostras coletadas antes da entrada da recolhedora, e as perdas após a colheita, obtidas na plataforma de recolhimento e no sistema de trilha, separação e limpeza da máquina. Para a determinação das perdas na pré-colheita, as armações foram colocadas nas parcelas demarcadas e os grãos sobre o solo foram recolhidos e levados à estufa. As perdas na plataforma de recolhimento foram determinadas interrompendo-se a operação ao final de cada parcela, dando marcha-ré na recolhedora e posicionando-se a armação na área onde somente a plataforma recolhedora havia passado, sendo os grãos encontrados no solo, recolhidos e suas massas determinadas. Para a determinação das perdas nos sistemas de trilha, separação e limpeza, posicionou-se ao acaso a armação na parcela, em sentido transversal ao movimento da recolhedora e dos grãos recolhidos.

As amostras para determinação da matéria seca foram coletadas posicionando-se a armação de ferro de $0,25 m^{2}(0,5 m \times 0,5 m)$ ao acaso nas parcelas, coletandose apenas o material passado pela máquina, sendo este acondicionado em sacos de papel e levado à estufa a $70^{\circ} \mathrm{C}$ por 48 horas e, em seguida, foi determinada sua real de deslocamento ( $\mathrm{m} \mathrm{s}^{-1}$ ); x: relação palha-grão, obtida pela relação da massa da matéria seca da palhada com a produtividade da cultura.

\section{RESULTADOS E DISCUSSÃO}

Verifica-se que o nível de ruído não foi afetado pelos fatores analisados (Tabela 1), diferindo dos resultados encontrados por SOUZA et al. (2004), que, ao trabalhar com velocidades de 2,0; 2,5 e 2,5 $\mathrm{km} \mathrm{h}^{-1}$ observaram aumento do nível de ruído próximo ao ouvido do operador ao utilizar menor velocidade. ZOPPELLO et al. (1995) e SOUZA (2001) afirmam que os implementos e as máquinas acionados pela TDP exigem menor força de tração e, nesse caso, o ruído é mais influenciado pela rotação e vibração dos órgãos internos transmissores de potência na máquina. Entretanto, os valores médios obtidos estão acima do limite máximo estabelecido pela NB 95 (ASSOCIAÇÃO..., 1987), bem como, acima do limite de 85dB(A) para oito horas de exposição diária, estabelecido pela NR-15 (MINISTÉRIO DO TRABALHO..., 2003). De acordo com a NR-15 o operador poderia realizar jornada de trabalho de apenas cinco horas diárias nessa máquina, sem o uso de protetor auricular. Para a capacidade de campo operacional (Tabela 1), verifica-se semelhança em

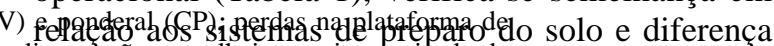

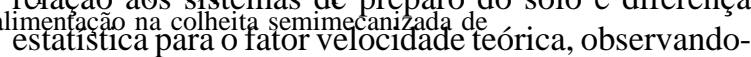
se, como esperado, aumento dessas variáveis com o aumento das velocidades teóricas de trabalho.

A análise de variância para os valores de

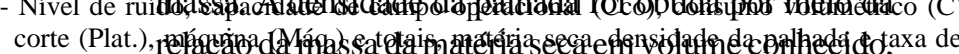
feijão. utilizando-se um becker de 640mL.

O fluxo de alimentação da máquina foi

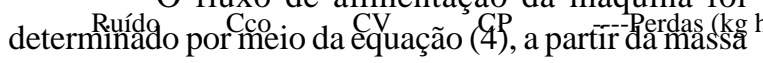

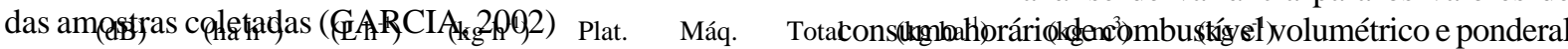

\begin{tabular}{|c|c|c|c|}
\hline Preparo convencional & 89,0a 0 (9an.e.v! $($, , $a+x)$ 8,9a & $37,2 \mathrm{a}$ & 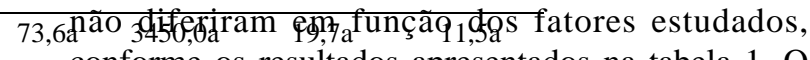 \\
\hline Plantio direto & $88,5 \mathrm{a} q=0,9 \mathrm{a} \quad 100187^{\mathrm{a}} \quad 8,8 \mathrm{a}$ & $47,2 \mathrm{a}$ & $97,2 \AA 0$ \\
\hline Velocidade $1\left(4,0 \mathrm{~km} \mathrm{~h}^{-1}\right)$ & $0,7 \mathrm{c} \quad 1040,5 \mathrm{a} \quad 8,6 \mathrm{a}$ & $44,1 \mathrm{a} \quad 37,5 \mathrm{ab}$ & $\mathrm{h}^{-1}$ \\
\hline \multirow{2}{*}{\multicolumn{3}{|c|}{ 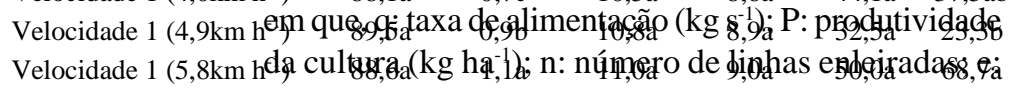 }} & 55,8\& o constu,na horárg,9gponderal, foi de 8,8 $\mathrm{kg} \mathrm{h}^{-1}$. Os valores \\
\hline & & & 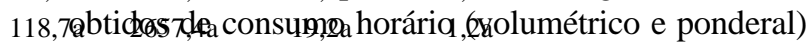 \\
\hline CV (\%) & 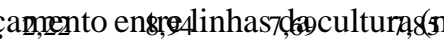 & 75x,clocida, \$e & 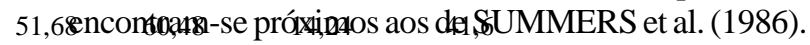 \\
\hline
\end{tabular}

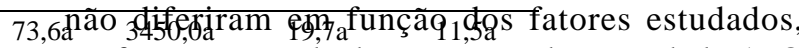

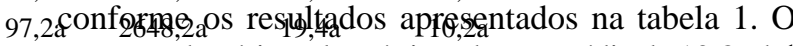

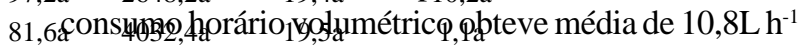

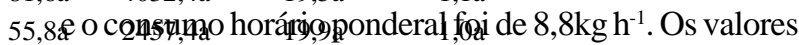

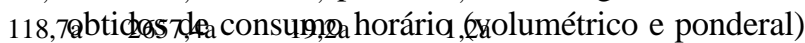

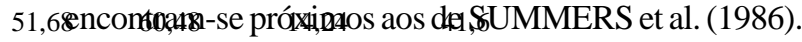

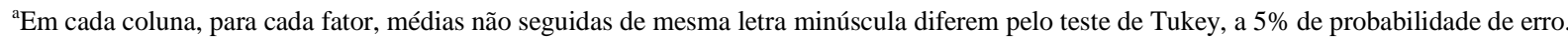


Observa-se que as perdas no sistema de plantio convencional foram da ordem de $4,0 \%$ e, no sistema plantio direto foram de $5,5 \%$ (Tabela 1 ), sem diferir entre, assim como as perdas ocorridas na plataforma de recolhimento e as perdas totais. As perdas da plataforma representaram de 42 a $58 \%$ das perdas totais, concordando com SILVA \& BEVITORI (1994), que embora tenham utilizado recolhedoraautopropelida, verificaram valores de perdas na plataforma de até $60 \%$ das perdas totais. As perdas na pré-colheita e no arranquio e no enleiramento manual, somadas foram muito baixas, razão pela qual elas foram consideradas desprezíveis.

No sistema de trilha, separação e limpeza da máquina (Tabela 1), as perdas também ocorreram na faixa de 42 a $58 \%$ das perdas totais e foram significativas em função do fator velocidade, com a velocidade 2 $\left(4,9 \mathrm{~km} \mathrm{~h}^{-1}\right)$, apresentando menores perdas em relação à velocidade $3\left(5,8 \mathrm{~km} \mathrm{~h}^{-1}\right)$. Os altos valores encontrados para o coeficiente de variação podem ser justificados pela alta variabilidade da amostra observada em vários estudos sobre perdas na colheita realizados em condições de campo, bem como naqueles com controle experimental (PINHEIRO NETO \& GAMERO, 1999; MESQUITA et al., 2002; CAMPOS et al., 2005). Amatéria seca, a densidade da palhada e o fluxo de alimentação da máquina não diferiram em função dos fatores analisados (Tabela 1), não influenciando o processo de perdas da máquina.

\section{CONCLUSÕES}

Os sistemas de preparo do solo (preparo convencional e plantio direto) e as velocidades de trabalho não influenciam o nível de ruído no posto do operador, os consumos horários volumétrico e ponderal, a taxa de alimentação da recolhedora e as perdas na plataforma da recolhedora e totais.

A velocidade V2 $\left(4,9 \mathrm{~km} \mathrm{~h}^{-1}\right)$ proporciona menores perdas no sistema de trilha, separação e limpeza durante a colheita do feijoeiro. A matéria seca, a densidade da palhada e a taxa de alimentação da máquina são semelhantes em função dos fatores analisados, porém as perdas ocorridas no sistema de trilha, separação e limpeza são menores na velocidade de $4,9 \mathrm{~km} \mathrm{~h}^{-1}$.

\section{REFERÊNCIAS}

ALCÂNTARA, J.P. et al. Avaliação de cultivares de feijoeiro (Phaseolus vulgaris L.) em diferentes densidades de semeadura e condições de ambiente. Ciência e Prática, Lavras, v.15, n.4, p.331-428, 1991.
ASSOCIAÇÃO BRASILEIRA DE NORMAS TÉCNICAS: Níveis de ruído aceitáveis: NBR 10152 (NB-95). Rio de Janeiro, 1987. 4p.

BALASTREIRE, L.A. Máquinas agrícolas. São Paulo: Manole, 1990. 310p.

CAMPOS, M.A.O. et al. Análise de perdas na colheita mecanizada de soja no estado de Minas Gerais. Engenharia Agrícola, Jaboticabal, SP, v.25, n.1, p.207-213, 2005.

CONAB. Série histórica de grãos: safra 1976/77 a 2006/ 07. Capturado em 30 set. 2007. Online. Disponível na Internet http://www.conab.gov.br/conabweb/.

GARCIA, R.F. Simulação do comportamento dinâmico de uma colhedora de feijão. 2002. 86f. Tese (Doutorado em Engenharia Agrícola) - Universidade Federal de Viçosa, Viçosa.

ELIAS, A.I. et al. Colheita mecanizada de feijão Phaseolus vulgaris L.. In: FANCELLI, A.L.; DOURADO-NETO, D. Feijão irrigado: estratégias básicas de manejo. Piracicaba: Publique, 1999. p.102-107.

EMBRAPA - Empresa Brasileira de Pesquisa Agropecuária. Sistema brasileiro de classificação de solos. Rio de Janeiro: EMBRAPA/CNPSO, 1999. 412p.

LOPES, A. et al. Protótipo de sistema instrumental para medição de consumo de combustível em tratores. In: CONGRESSO BRASILEIRO DE INFORMÁTICA APLICADA À AGROPECUÁRIA E À INDUSTRIA, 4., 2003, Porto Seguro. Anais... Porto Seguro: SBIAgro, 2003. $1 \mathrm{Cd}$.

MANTILLA, E.N.; RAMOS, J.N. Metodología de cálculo de órganos trilladores del tipo cilindro cóncavo. Revista Ciencias Técnicas Agropecuarias. La Habana, v.7, n.2., p.75-79, 1998.

MESQUITA, C.M.; GAUDÊNCIO, C.A. Medidor de perdas na colheita de soja e trigo. Londrina. Com. Tec. Cent. Nac. Pesq. Soja/EMBRAPA, 1982. N.15, p.1-8.

MESQUITA, C.M. et al. Perfil da colheita mecânica da soja no Brasil: safra 1998/1999. Engenharia Agrícola, Jaboticabal, v.22, n.3, p.398-406, 2002.

MIALHE, L.G. Características do ensaio de máquinas agrícolas. In: _____ Máquinas agrícolas: ensaio e certificação. Piracicaba: FEALQ, 1996. p.37-68.

MINISTÉRIO DO TRABALHO E DO EMPREGO. Atividades e operações insalubres (115.000-6): NR-15. Capturado em 12 dez. 2003. Online. Disponível na Internet http:// www.mtb.gov.br.

MORAES, L.B. et al. Máquinas para colheita e processamento de grãos. Pelotas: UFPel, 1996. 153p.

PINHEIRO NETO, R.; GAMERO, C.A. Efeito da colheita mecanizada nas perdas quantitativas de grãos de soja (Glycine $\max ($ L.) Merrill). Energia na Agricultura, Botucatu, v.14, n.1, p.69-81, 1999.

SANTOS, M.L.; BRAGA, M.J. Aspectos econômicos. In: VIEIRA, C. et al. Feijão: aspectos gerais e cultura no estado de Minas Gerais. Viçosa: UFV, 1998. p.19-53. 
SILVA, C.C.; BEVITORI, R. Colheita e beneficiamento de feijão. Informe Agropecuário, Belo Horizonte, v.17, n.178, p.63-65, 1994.

SILVA, J.G. et al. Desempenho de métodos de colheita em função de manejos empregados na cultura do feijoeiro. In: CONGRESSO NACIONAL DE PESQUISA DE FEIJÃO, 8., 2005, Goiânia. Anais... Santo Antônio de Goiás: Embrapa Arroz e Feijão, 2005. p.615-618.

SILVA, J.G. Mecanização sem esforço. Cultivar máquinas Pelotas, 2004. V.3, n.36. 10p. (Encarte: Caderno Técnico).

SILVA, J.G. et al. Colheita direta do feijoeiro com colhedora automotriz. In: COBUCCI, T. (Ed.). Avanços tecnológicos com a cultura do feijoeiro comum no sistema de plantio direto. Santo Antônio de Goiás: Embrapa Arroz e Feijão, 1999. 36p. (Embrapa Arroz e Feijão. Documentos, 100)

SILVA, J.G.; FONSECA, J.R. Colheita. In: ZIMMERMANN, M.J.O. Cultura do feijoeiro comum no Brasil. Piracicaba: POTAFOS, 1996. p.523-541.
SILVA, J.G.; SILVEIRA, P.M. Colheita mecanizada do feijoeiro. Informe Agropecuário, Belo Horizonte, v.25, n.223, p.138144, 2004.

SOUZA, C.M.A. Avaliação e simulação do desempenho de uma colhedora de feijão (Phaseolus vulgaris L.). 2001. 113f. Dissertação (Mestrado em Mecanização Agrícola) Universidade Federal de Viçosa, Viçosa, MG.

SOUZA, L.H. et al. Níveis de ruído emitidos por uma recolhedora-trilhadora de feijão. Engenharia Agrícola, Jaboticabal, v.24, n.3, p.745-749, 2004

SUMMERS, J.D.et al. Draft relationships for primary tillage in Oklahoma soils. Transations of the ASAE, Saint Joseph, v.29, n.1, p.37-39, 1986.

ZOPPELLO, G. et al. Aziende agricole, il rischio da rumore ed il D.Lgs 277/91. Macchine e Motori Agricoli, Bologna, v.2, n.10, p.9-16, 1995. 